\title{
ASSESSING THE CONTRIBUTION OF INSTRUCTIONAL TECHNOLOGY IN THE TEACHING OF PRONUNCIATION
}

\author{
Antônio R.M. Simões \\ Department of Spanish and Portuguese \\ University of Kansas, Lawrence, USA, 66045-2166 \\ simoes@ raven.cc.ukans.edu
}

\begin{abstract}
This investigation discusses the implementation of computerbased teaching of Spanish pronunciation, especially intonation, in the classroom. It examines the potential and the actual use of a technologically-based system, and the results of such a system in the improvement of students' pronunciation in one semester of instruction. The effects of instructional technology were studied through recordings of students made at the beginning and end of a semester. Their recordings were evaluated by native speakers of Spanish in two ways. First, native speakers evaluated the overall pronunciation of each recording according to a scale from $0-8$, using 8 as the equivalent of native speaker pronunciation. Then, the native speakers were asked to give their intuitive evaluation of the language musicality of the same recordings. In this second task, native speakers were asked to decide if the recordings of second language learners sounded: (0) not like singing, (1) a little like singing, (2) much like singing, and (3) so much singing that it was annoying.
\end{abstract}

Quantitative analysis of the overall results is still undetermined, despite possible improvement in nearly $40-50 \%$ of participating students. More promising and revealing, however, is the qualitative analysis of the data, and the experiment itself, all of which reveal significant information in favor of the present technology.

\section{INTRODUCTION}

When one person notices that another person "sings" in his/her speech, it may be very difficult to understand the remark. On the other hand, the perception of "singing" in a remark indicates a deviation from a given linguistic norm. This subjective evaluation of other people's speech may be noted in many different contexts. A given linguistic community may remark that another community sings, or an individual might notice that another individual in the same community sings. Likewise, a northern Spaniard may say that a southern Spaniard sings, just as a Parisian may notice that a southerner in France sings, or a Brazilian from the south may say that people from Rio sing, and likewise, people from Rio may remark that southerners speak "cantadinho," namely singing. Instances of this sort are numerous.

In terms of second language acquisition, "singing" in foreigners may signal a deviation from the given norm in the target language. In the classroom, however, it is very difficult to discuss and correct unwanted musicality, on a strictly intuitive basis. Teachers and students need more tangible speech factors to work with. Consequently, this paper explores the phonetic correlates of language musicality, or "singing," in the pronunciation of second language learners, with the support of instructional technology.

The motivation to analyze musicality in natural languages is manifold. The many comparisons existent in data on speech of the kind studied here may lead to a better understanding of language prosody. Studies of this kind might help to improve speech recognition systems, as well as to improve our theoretical understanding of a number of issues, e.g. the natural tendency to intonation universals $[3,4,5,13]$.

Another motivating factor that underlies this study has to do with a pedagogical concern expressed either in teaching manuals [1], or by language teachers themselves for whom the misuse of prosodic patterns can be embarrassing. Latin American countries offer an interesting illustration of such misuse. It is common for native speakers of Spanish to say that many times foreigners speak Spanish as if they were singing. This phenomenon, often imitated on television and radio shows, might be explained acoustically by prosodic factors such as a higher number of pauses, mistaken direction of intonation contours, sentence stress, and high-falls in nuclear contours. The term "prosody" is used here as cover terms for non-segmental elements of speech, such as intonational, duration, stress, pause, and rhythm.

It has been argued that the relationship between subjectvely defined singing and the acoustic signal cannot be measured. For example, Olle Kjellin (personal communication) claims that the main factor underlying the impression of singing "is our ear's keenness to detect and make us aware of any deviation from the expected prosody, because it usually conveys important paraverbal information." Thus, it is pointless to search for physical factors creating the impression of singing. Kjellin explains further his view with a metaphor of a "carrier wave," which I also like and other scholars have also used [3]: "prosody, especially rhythm, is the fundamental "carrier wave" for transmitting spoken language from the speaker to the listener and is probably essential for the auditory perception. Prosody is not primarily meant for the expression of feelings, (...)." 
I argue that if a consensus is found among native speakers about the singing characteristics of second language learners, then some particular speech patterns create the impression of singing. An initial step has been taken in this study to search for these physical patterns. Yet, regardless of which side we take in this discussion, intonation remains an essential component of language teaching, and learning, and as such it needs to be kept as a component of language curricula. Judicious use of instructional technology will provide students and teachers with the understanding of intonation patterns and, consequently, with efficient classroom interaction for teaching and learning pronunciation.

\section{EXPERIMENTAL PROTOCOL}

During the fall semester of 1995 I used the speech analysis system CECIL, which was originally designed for research in prosody $[7,8,10]$, as a regular component of an undergraduate class in Spanish phonetics. The computer-based system CECIL was used primarily to teach intonation patterns of Latin American Spanish of the "high-lands," commonly considered the standard Spanish in the United States [2].

The assessment of students overall pronunciation, as well as the particular analysis of the musicality in their speech, was made using recorded readings of texts made by 12 students, taken randomly from a group of 25 students using this system. The readings were taken from the course textbook [2], and the recordings were made at the beginning and at the end of the semester. Three types of passages were selected: two were fragments from dialogues, and one was a set of three sentences. These recording fragments were then mixed randomly, and given to 13 native speakers of Spanish to make an evaluation of the readings. Five native speakers made an evaluation of the overall performance of the recordings using a scale from zero to eight, where eight was the equivalent of native-speaker reading. Eight other native speakers of Spanish made an evaluation of the singing-like characteristics of the readings in a scale from $0-3$, so that " 0 " meant "not like singing," " 1 " meant mean "a little like singing," "2" meant "much like singing," and "3" meant "so much singing that it was annoying."

Table 1 shows that evaluators felt that students S11 and S14 improved in their overall pronunciation, and that students S08 and S05 had some improvement, but not as much. Blank cells under "change in overall pronunciation" indicate indetermination. Then, we observe that students S06, S09, and S11 had the worst overall pronunciation, and students S04 and S05 the best. Blank cells, or cells with one or two asterisks indicate that scores were in between lowest and highest. In respect to singing, students S06, S08, S09, S11, S12, S14, and S15 did sound much like singing in the first recording. In the second recording students S08, S09, S12, and S14 were perceived as singing. In other words, three students sounded less like singing in the second recording. Blank cells indicate that singing was not noticed or only slightly noticed. The next section will discuss these results.

\begin{tabular}{|c|c|c|c|c|c|}
\hline Student & \multicolumn{2}{|c|}{$\begin{array}{c}\text { Change in } \\
\text { overall } \\
\text { pronunciation }\end{array}$} & \multicolumn{2}{|c|}{ Score range } & \multicolumn{2}{c|}{ Singing } \\
\hline S03 & & $*$ & $*$ & & \\
\hline S04 & & & $* * *$ & & \\
\hline S05 & & & $* * *$ & & \\
\hline S06 & & $* * *$ & & $\mathrm{y}$ & \\
\hline S07 & & $* *$ & & & \\
\hline S08 & oo+++ & & $* *$ & $\mathrm{y}$ & $\mathrm{y} !$ \\
\hline S09 & & $* * *$ & & $\mathrm{y}$ & $\mathrm{y}$ \\
\hline S10 & & & $* *$ & & \\
\hline S11 & $\mathrm{o}++++$ & $* * * * *$ & & $\mathrm{y}$ & \\
\hline S12 & & $* *$ & & $\mathrm{y}$ & $\mathrm{y}$ \\
\hline S14 & $\mathrm{o}++++$ & & $*$ & $\mathrm{y} !$ & $\mathrm{y}$ \\
\hline S15 & $\mathrm{ooo++}$ & $* *$ & & $\mathrm{y} !$ & \\
\hline
\end{tabular}

Table 1: Results from the evaluation made by native speakers of Spanish. Student names have been replaced by letters and numbers. Other abbreviations are: "o" for "no change," "+" for "improvement," "rec" for "recording", and "y" for "yes/singing." The asterisks represent the number of times the student was considered in the lowest or highest scores. For example, student S04 was evaluated five times with the highest scores, or the best pronunciation.

The context in which this experiment took place, namely class activities to teach pronunciation in a computer-based environment was as follows. The classroom had a computer PC, a data pad or a special overhead projector to be coupled with a computer, a tape player, a microphone, a large screen, and the necessary parts to connect these peripherals. In this setting, the classes discussed intonation in terms of perception and production. The development of perceptual feeling for intonation may be accomplished in several ways. One is the use of a prerecorded spoken fragment in a regular audio cassette, or of recordings from a computer diskette. For instance, a recording can be played and students are asked to indicate the kinds of intonation contours they perceive. After the students attempt to recognize the main contours, they are presented with a graphic of the fragment under analysis on the large screen. This interplay may last the whole hour if needed. One of its many advantages is that it can help even students considered tone deaf develop a better recognition of intonation contours. The subsequent step is production, in terms of intonation mimicry. Other activities will aim at the application of these skills with the actual use of discourse.

\section{DISCUSSION}

The data collected for this study are still being analyzed. However, this project can already describe the advantages of using a system like CECIL, in any of its versions, as an instructional as well as a research tool. Teachers using this system will be able to explore their understanding of prosody, especially intonation, along with their students.

The space here is too limited for a detailed comparison with other systems for speech analysis, as it has been done elsewhere $[9,11]$. In my personal experience, CECIL has shown to be the most 
attractive system for working with the acoustics of speech. Nevertheless, my main reasons to work with CECIL and not for example with another excellent system like CSRE [11], are its price, adaptability, and its specific design for prosodic analysis. CECIL can create numerical files exportable and convertible to data processors for graphic, statistical and other numerical analyses. Consequently, it can create desk top graphics, and provide sophisticated images not only of pitch analysis, but also of loudness, lengthening, and pauses, at the acoustic level. It is a system that seems to work with any sound cards, and its fundamental frequency trace is the best one I have found. It has an immediate playback of any part of the recording, and at different speeds, along with information essential for research, as well as the teaching of prosody. The advantages thus are numerous. The feature I have used most in the classroom is the one that shows different windows for multifaceted analysis of the same recordings or of two different recordings at the same time.

In the analysis of two different recordings, for example, one can easily place a model of intonation from any language in one window, and ask the students to imitate the model in another window, as shown in figure 1. This is not to be confused with attempts made in the classroom to have students mimick images of speech soundwave produced through a number of popular speech software. To ask students to imitate soundwaves is antipedagogic and distressful, because it is hopeless to attempt to imitate even our own soundwave . On the other hand, it is relatively much easier to understand and imitate important intonation contours at key points of spoken discourse, as rendered in fundamental frequency traces. In addition, these images might also help students who might be tone deaf, and students unable to distinguish stressed from unstressed syllables. The use of technology of this type is not time consuming: in a semester program of 50-minute class meetings, three times a week, the use of such a system to teach prosody in a language such as Spanish requires between 5-10 meetings per semester

A word of caution: we must not confuse the simplicity and efficiency of this or any other system with the lack of knowledge of the subject we deal with. For example, teachers who would like to use this system for a better understanding of prosody need to have a good knowledge of prosody before using this technology in the classroom. While this is obvious for some, it is often disregarded, and as a result, the benefits are not apparent. Such a system will improve an already acquired knowledge of language prosody and make the students understand it much faster, because it is visually powerful.

The system just described had been in use occasionally in my classrooms since 1993, to compensate for the limited discussion of intonation in textbooks [2]. By 1995, it became such an essential part of my program that I made its use a regular component of my phonetics class, especially for the teaching of intonation. Ideally, this system should operate in a network of approximately ten PC-386 or higher terminals. Such a network will give students autonomy to use the system more efficiently, at their own pace. It goes without saying that other applications will ensue, since other language studies could share this system.
In regard to the facts in table 1 , the students evaluated were mostly in their junior and senior years of their undergraduate program, and two were graduate students. At this level of language proficiency, improvement is slow, compared to the improvement we observe in students starting at the very beginning level of language instruction. The results of overall pronunciation show that four students out of twelve improved their overall pronunciation. The others showed no change. There are cases in which the evaluation was lowest in the second recording. This is difficult to explain, but as educators know, a classroom is composed of a variety of students, some with excellent study habits, and others without good study habits, and some students simply are not interested. The number of these cases of lower performance were low, 2 out of 12, and so as to be negligible. Approximately $40 \%$ of the students showed no changes and $43 \%$ improved their overall pronunciation.

In respect to the issue of singing there was also improvement, although in the case of student S08, there seems to be an increase in singing-like pronunciation. The "y" means that five-six evaluators, out of eight, felt that the students simply sang or sang too much. In the case of "y!," seven-eight evaluators agreed that there was singing. From the facts depicted in table 1, improvement was observed in students S06, S11, and S15. The other students did not change or did not sing. Also interesting are the results across table 1. Students S04 and S05 showed no overall change, nor change in singing, which is not surprising given their advanced language proficiency. These same students were also considered as having the best performance in overall pronunciation. They are not considered to sing. On the other hand, students S06, S09, and especially S11, who were considered to sing, have a problematic overall pronunciation, given their lowest scores range.

Given these results, I find that there was consensus among the evaluators that some students were considered to sing. By examining the recordings of these students considered to sing, I found that their speaking style does have some particular prosodic patterns of interest. Their hesitations create more pauses than expected, some intonation contours are in a range of fundamental frequency larger than the Spanish model, their vowels lengthen in a rise-fall pitch, and intonation contours are often reversed. A recurrent pattern of sentence stress was observed among these students, something which deserves attention. Students considered to sing often gave a double sentence stress before pauses. This phenomenon is still being analyzed, but it happens especially in words with word stress on the next-to-last syllable. For example, the Spanish word "presidente" has only one primary stress on the syllable "-den-," [pre.si.dén.te], in a broad phonetic transcription. Some students considered to sing "double-stressed" or "double-accented" these words on the stressed and poststressed syllables: *[pre.si.dén.té]. Perhaps this can be explained by a common tendency in Spanish to strengthen postonic syllables in prepausal position, as discussed in [11].

Figure 1 illustrates one of the several acoustic correlates of singing-like pronunciation. The Spanish sentence "No, no ha 
habido ningún tipo de problema," taken from one of the dialogues of the readings, illustrates a reversed intonation contour, using as reference a native-speaker pronunciation. The two images superimposed show on the top the model to be imitated, and below a fragment from a recording made by one of the twelve students. While the model carries a falling contour in the word "problema," the student mistakenly pronounced the same word with a rising contour. The mistake is further aggravated with the lengthening of the vowel [e] as indicated by the colon (:). Figure 1 contains one of the many examples found in analyses of the recordings. The mistaken patterns discussed here are in fact common patterns among students who speak Spanish with a nonnative musicality.

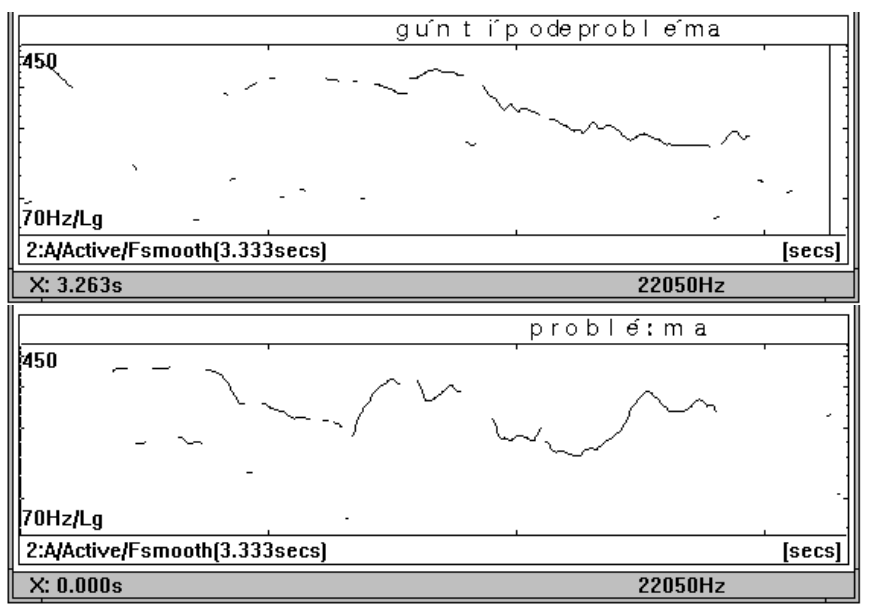

Figure 1: Superimposed intonation contours of the Spanish sentence "No, no ha habido ningún tipo de problema," (No, there has been no problem at all). On the top, the figure shows a native-speaker model with a falling Fo trace contour in the word "problema," and below there is the Fo trace of a recording of the same sentence by one student, who spoke with a reversed intonation contour at the point of the word "problema."

\section{CONCLUSION}

According to recordings of readings made by twelve non-native speakers of Spanish, there is a relationship between subjectively defined singing and the acoustic signal. The most common acoustic patterns, most likely to be linked to singing-like characteristics, are: mistaken pauses, larger Fo range, mistakenly lengthened vowels, reversed Fo contours, and a phenomenon identified provisionally as double sentence stress in prepausal position. It is hoped in this investigation that by pointing out the non-desirable prosodic patterns, teachers will be able to use this information in their classroom interaction.

The analysis of the assessment made by native speakers as well as the performance of second language learners in this article is still in progress. However, the study already shows the advantages of this system not only for research purposes, but also for the teaching of pronunciation, in particular of intonation. Furthermore, the experience with the computer-based instruction shows a number of advantages: this system can be used autonomously outside class, and it requires only about 5-10 meetings per semester to teach intonation, both in terms of perception and production. Although intonation is shown graphically in terms of fundamental frequency tracing only, this system has proven to be very effective.

\section{REFERENCES}

The works in this reference list indicated with an asterisk, were not mentioned in the discussion. They are included here because of their importance in this area of research.

1. Adriaen, Monique, 1990. La phonétique (manuscript). York, Canada: York University.

2. Barrutia, Richar and Tracy D. Terrell 1982. Fonética y fonología españolas. New York: John Wiley.

3. "Intonation is the broad undulation of the pitch curve that carries the ripples of accent on its back."

Bolinger, Dwight, 1975. Aspects of language, second edition. New York: Harcourt Brace Jovanovich, 48.

4. _ 1978. "Intonation across languages," J.

Greenberg, C.A. Ferguson, and E.A. Moravcsik, eds., Universals of human language, Vol. 2, Stanford: Stanford University Press, pp. 471-524.

5. Cruttenden, Alan 1986. Intonation. Cambridge Univ. Press

6. * Delattre, Pierre 1981. Studies in comparative phonetics: English, German, Spanish, and French.

7. Hunt, G. 1992. Interpreting CECIL: Gathering and interpreting acoustic phonetic data. Waxhaw, N.C.: Summer Institute of Linguistics.

8. How to use CECIL: A tutorial for the SIL speech analysis system. Waxhaw, N.C.: Summer Inst. of Linguistics, 1991.

9. Mann, V. 1987. Review of DSPS real-time signal lab by Robert Morris. Asha, 29 (11):64-65.

10. Owen, E. and R. Kelso 1992. CECIL reference manual. Waxhaw, N.C.: Summer Institute of Linguistics.

11. Read, C., E.H. Buder, and R.D. Kent 1990. Speech analysis systems: A survey. Journal of Speech and Hearing Research, June, 33:363-74.

12. Simões, Antônio R.M. (in press). Duration as an element of lexical stress in Spanish discourse: an acoustical analysis. Hispanic lnguistics.

13 * Sundberg, Johan, Lennart Nord, and Rolf Carlson, editors, 1991. Music, language, speech, and brain : proceedings of an international symposium at the Wenner-Gren Center. Stockholm, Sweden, 5-8 September 1990. London: MacMillan Press Scientific and Medical.

14 Vaissière, Jaqueline, 1983. "Language-independent prosodic features," A. Cutler and D.R. Ladd, eds., Prosody: models and measurements, Berlin: Springer, pp. 53-66. 